\title{
Acute effects of leptin require PI3K signaling in hypothalamic proopiomelanocortin neurons in mice
}

\author{
Jennifer W. Hill, ${ }^{1}$ Kevin W. Williams, ${ }^{1}$ Chianping Ye, ${ }^{2}$ Ji Luo, ${ }^{3}$ Nina Balthasar, ${ }^{4}$ Roberto Coppari, ${ }^{1}$ \\ Michael A. Cowley, ${ }^{5}$ Lewis C. Cantley, ${ }^{3}$ Bradford B. Lowell, ${ }^{2}$ and Joel K. Elmquist ${ }^{1}$ \\ 1Division of Hypothalamic Research, Department of Internal Medicine and Department of Pharmacology, \\ University of Texas Southwestern Medical Center, Dallas, Texas, USA. 2Division of Endocrinology, Beth Israel Deaconess Medical Center, \\ Boston, Massachusetts, USA. ${ }^{3}$ Department of Systems Biology, Harvard Medical School, and Division of Signal Transduction, \\ Beth Israel Deaconess Medical Center, Boston, Massachusetts, USA. ${ }^{4}$ Division of Physiology, University of Bristol, Bristol, United Kingdom. \\ ${ }^{5}$ Division of Neuroscience, Oregon National Primate Research Center, Oregon Health and Science University, Beaverton, Oregon, USA.
}

\begin{abstract}
Normal food intake and body weight homeostasis require the direct action of leptin on hypothalamic proopiomelanocortin (POMC) neurons. It has been proposed that leptin action requires PI3K activity. We therefore assessed the contribution of PI3K signaling to leptin's effects on POMC neurons and organismal energy balance. Leptin caused a rapid depolarization of POMC neurons and an increase in action potential frequency in patch-clamp recordings of hypothalamic slices. Pharmacologic inhibition of PI3K prevented this depolarization and increased POMC firing rate, indicating a PI3K-dependent mechanism of leptin action. Mice with genetically disrupted PI3K signaling in POMC cells failed to undergo POMC depolarization or increased firing frequency in response to leptin. Insulin's ability to hyperpolarize POMC neurons was also abolished in these mice. Moreover, targeted disruption of PI3K blunted the suppression of feeding elicited by central leptin administration. Despite these differences, mice with impaired PI3K signaling in POMC neurons exhibited normal long-term body weight regulation. Collectively, these results suggest that PI3K signaling in POMC neurons is essential for leptin-induced activation and insulin-induced inhibition of POMC cells and for the acute suppression of food intake elicited by leptin, but is not a major contributor to the regulation of long-term organismal energy homeostasis.
\end{abstract}

\section{Introduction}

The rising rate of obesity in Western countries has led to intensified efforts to understand the molecular and neuroanatomic mechanisms underlying coordinated control of energy balance in the face of abundant food and high-energy-density diets. One key metabolic signal is the adipocyte-derived hormone leptin. Leptin circulates in proportion to stored body fat, and lack of leptin or long-form leptin receptors in the brain produces severe obesity (1-3). One identified leptin-responsive cell is the proopiomelanocortin (POMC) neuron. POMC cells are located in the arcuate nucleus (ARC) of the hypothalamus and are directly activated by circulating leptin $(4,5)$. Indeed, direct leptin action on POMC neurons is required for normal body weight homeostasis, because deletion of the leptin receptor in POMC neurons alone causes increased adiposity (6).

Leptin activates a cytokine receptor, inducing JAK/STAT pathway signaling and leading to alterations in transcription of several target genes, including the gene encoding POMC $(7,8)$. It has been established that STAT3 signaling plays a major role in leptin's control of energy homeostasis (9). However, many acute responses to leptin do not necessitate altered gene expression. For example, leptin has been shown to depolarize and increase POMC neuronal activity via activation of a nonselective cation current

Nonstandard abbreviations used: ACSF, artificial cerebrospinal fluid; AgRP, agouti-related protein; ARC, arcuate nucleus; NTS, nucleus of the solitary tract; PIP3, PtdIns $(3,4,5) \mathrm{P}_{3}$; POMC, proopiomelanocortin.

Conflict of interest: The authors have declared that no conflict of interest exists. Citation for this article: J. Clin. Invest. 118:1796-1805 (2008). doi:10.1172/JCI32964. within minutes of leptin application (5). The acute modulation by leptin of cellular activity is conserved in several brain areas and suggests that neurons are sensitive to rapid changes in leptin levels $(5,10-13)$. Moreover, this change in cellular activity might correlate to a leptin-induced change in physiology or behavior.

Recent attention has focused on the potential role of the PI3K pathway in inducing rapid effects of leptin in hypothalamic neurons (14, 15). In numerous cell types, PI3K acts in a heterodimeric form consisting of $185-\mathrm{kDa}$ regulatory (p85) and $1110-\mathrm{kDa}$ catalytic ( $\mathrm{p} 110)$ subunit. Under normal conditions, signaling by p $85-\mathrm{p} 110$ dimers is partially inhibited by an excess of $\mathrm{p} 85$ subunits (16). Thus, reduction of p85 levels through deletion of a single isoform can paradoxically upregulate PI3K signaling, while deletion of multiple isoforms prevents catalytic activity and eliminates signaling $(17,18)$. PI3K is activated by phosphorylated IRS proteins, allowing the enzyme to catalyze the phosphorylation of PtdIns $(4,5) \mathrm{P}_{2}$ (PIP2) to PtdIns $(3,4,5) \mathrm{P}_{3}$ (PIP3). PIP3, in turn, may recruit downstream molecules carrying PIP3-binding domains or modify channel activation $(19,20)$.

While recent work suggests that leptin activates PI3K signaling in the hypothalamus $(1,2,14,21-27)$, the role of a central leptin$\mathrm{PI} 3 \mathrm{~K}$ pathway in short- and long-term energy regulation remains to be established. We therefore tested the hypothesis that PI3K signaling in POMC neurons is necessary for normal leptin responsiveness. We first examined the activity of POMC neurons in the presence of leptin, insulin, and PI3K antagonists. Second, using the cre/loxP system, we eliminated all of the major p 85 isoforms expressed in POMC cells of the ARC (28) and investigated the resulting impact on leptin signaling and energy homeostasis. 
A
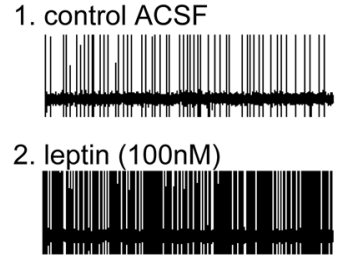

3. after washout of leptin

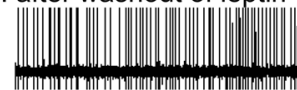

4. leptin and wortmannin

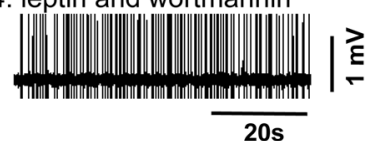

B

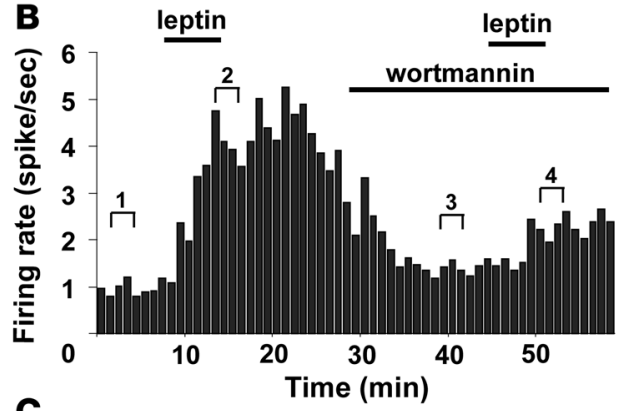

C

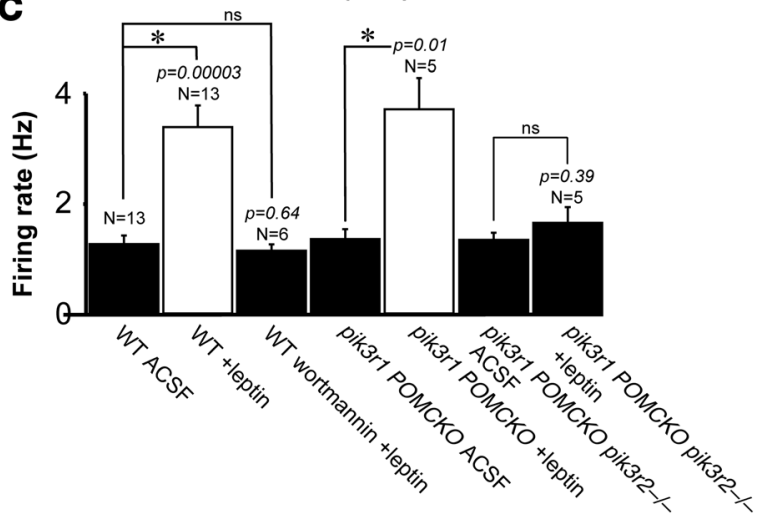

Figure 1

Leptin increases POMC neuronal activity in a PI3K-dependent manner. (A) Sample traces of loose-patch recording in control ACSF, with leptin (100 nM), after wash to control ACSF, and in the presence of the PI3K inhibitor wortmannin (100 nM). (B) Histogram showing spike frequency of the same neuron in $\mathbf{A}$ organized into 20-s epochs. (C) Leptin-induced increase in neuronal activity of identified POMC neurons. $P$ values compared with control ACSF are shown.

\section{Results}

PI3K blockade inhibits leptin-induced activation of POMC neurons. Loosepatch recordings of POMC neurons were performed in intact mice that express GFP under the control of the POMC promoter (referred to herein as WT) $(5,29,30)$. Leptin (100 nM) increased the firing rate in 12 of 13 POMC neurons (artificial cerebrospinal fluid [ACSF], $1.2 \pm 0.1 \mathrm{~Hz}$; leptin, $3.4 \pm 0.4 \mathrm{~Hz} ; n=12, P=0.00003$; Figure 1A). Similar to previous reports, the leptin-induced increase in firing rate was reversible within approximately 15 minutes (12, 13, 31, 32). The selective PI3K antagonist wortmannin (100 nM) was used to delineate a PI3K contribution to the leptin-induced excitation of POMC neurons. Preapplication of wortmannin blocked the leptin-induced activation of all POMC cells examined (control, $0.9 \pm 0.1 \mathrm{~Hz}$; wortmannin and leptin, $1.1 \pm 0.1 \mathrm{~Hz} ; n=6$, $P=0.22$; Figure $1 \mathrm{~B}$ ). This suggests that leptin directly excites POMC neurons via a PI3K-dependent mechanism.

Whole-cell patch-clamp recordings were made to assess the effects of leptin on membrane potential. In current clamp mode, leptin caused rapid depolarization from rest in 19 of 23 POMC neurons (6.2 $\pm 0.5 \mathrm{mV}$; resting membrane potential, $-44.8 \pm 0.8 \mathrm{mV} ; n=19$; Figure 2). This depolarization was accompanied by a $26 \%$ decrease in the whole-cell input resistance (control, $1,052.3 \pm 202.0 \mathrm{M} \Omega$; leptin, $780.2 \pm 115.8 \mathrm{M} \Omega ; n=9, P=0.008$; Figure 3). Extrapolation of the linear slope conductance in control and leptin-containing ACSF revealed a reversal potential of $-28.1 \pm 2.3 \mathrm{mV}(n=9$; Figure 3$)$, which was similar to previous reports that suggested a non-selective cation conductance may be involved in the leptin-induced depolarization of hypothalamic neurons $(5,33)$.

Selective PI3K inhibitors were then used to determine the role of $\mathrm{PI} 3 \mathrm{~K}$ in the leptin-induced depolarization of POMC neurons. Wortmannin $(100 \mathrm{nM})$ prevented the leptin-induced depolarization in 4 of 5 POMC neurons $(0.7 \pm 0.7 \mathrm{mV} ; n=5$; Figure 2$)$. Similarly, the PI3K inhibitor LY294002 $(10 \mu \mathrm{M})$ blocked the leptin-induced depolarization in 8 of 10 POMC neurons $(0.5 \pm 0.8 \mathrm{mV})$. LY294002 also prevent- ed the leptin-induced decrease in whole-cell input resistance (control, 1,094.1 \pm 182.0 M ; LY294002 and leptin, 1,015.5 $\pm 158.3 \mathrm{M} \Omega$; $n=10, P=0.76)$. In contrast, a MAPK inhibitor, PD98059 $(50 \mu \mathrm{M})$, failed to prevent leptin-induced depolarization in 8 of 10 POMC neurons $(4.8 \pm 0.7 \mathrm{mV} ; n=8)$, which suggests that acute activation of POMC neurons is independent of MAPK signaling. Some neurons were voltage-clamped at membrane potentials between -50 and $-70 \mathrm{mV}$ to monitor changes in whole-cell current during bath application of leptin. Leptin application resulted in an inward current in all WT neurons examined $(-15.5 \pm 3.2 \mathrm{pA}, n=5)$. In agreement with the leptin effect on membrane potential, the leptin-induced inward current was prevented by LY294002 $(-3.4 \pm 4.0 \mathrm{pA}, n=5)$. Together, these pharmacological data indicate that a PI3K-dependent mechanism is required for the leptin-induced activation of POMC neurons.

Development of Pik3r1 POMCKO Pik3r2 $2^{-/-}$mice. To generate mice with impaired PI3K signaling in POMC neurons, we crossed mice in which loxP sites flank exon 7 of the p $85 \alpha$ gene Pik $3 r 1$. This exon is critical for the production of functional $\mathrm{p} 85 \alpha$ and its splice variants p55 $\alpha$ and p50 $\alpha$ (34) (Figure 4A). These mice were crossed with transgenic mice expressing Cre driven by Pomc regulatory elements (6). By interbreeding the resulting mice with Pik3r2 $2^{-/-}$(35) and B6;129-Gt(ROSA)26Sor ${ }^{\text {tm2Sho } / J ~ m i c e ~(T h e ~ J a c k s o n ~ L a b o r a t o r y), ~}$ we were able to produce mice globally deficient in p $85 \beta$ but lacking p $85 \alpha$ only in POMC neurons with concomitant GFP reporter expression (Pik3r1 POMCKO Pik3r2-l-). For all experiments, these mice were compared with littermates not expressing POMC-cre

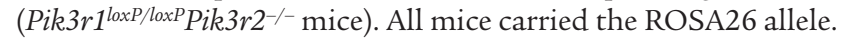

In the rodent brain, POMC expression is limited to the ARC of the hypothalamus and the nucleus of the solitary tract (NTS) (36, 37). Cre recombinase expression in this POMC-cre model has been previously shown to recapitulate this expression pattern, with greater than $90 \%$ of $\alpha$-melanocyte-stimulating hormone-positive neurons able to drive reporter expression (6). We performed PCR on genomic DNA from the ARC, dorsomedial hypothalamic 

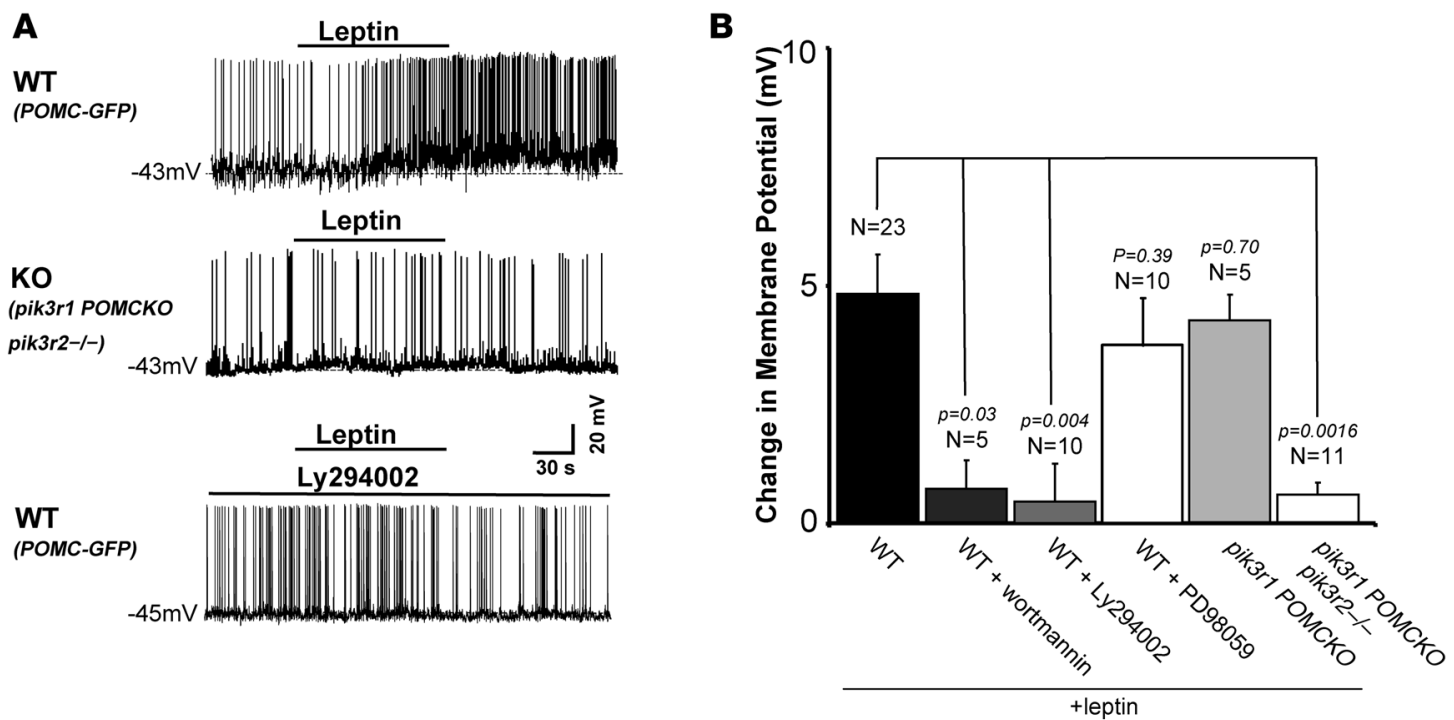

Figure 2

Leptin causes depolarization of POMC neurons via a PI3K-dependent mechanism. (A) Current-clamp recordings demonstrated that disruption of $\mathrm{PI} 3 \mathrm{~K}$ signaling occluded the leptin-induced depolarization of POMC neurons from rest. Top: Characteristic leptin-induced (100 nM) depolarization of WT neurons. Middle: Absence of leptin-induced depolarization in POMC neurons from Pik3r1 POMCKO Pik3r2-/- mice. Bottom: Leptin failed to depolarize POMC neurons in the presence of the PI3K inhibitor LY294002 (10 $\mu \mathrm{M})$. (B) Leptin-induced responses of identified POMC neurons from WT, Pik3r1 POMCKO, and Pik3r1 POMCKO Pik3r2-/- mice. P values compared with WT are shown.

nucleus, paraventricular nucleus, NTS, and control areas of the brain using primers surrounding the targeted exon 7 region. In these animals, deletion of the 103-bp loxP-flanked region of exon 7 of Pik3r1 was limited to the ARC and the NTS (Figure 4B).

We examined whether POMC neurons developed normally in these mice. No change was seen in their number or size (Supplemental Figure 1; supplemental material available online with this article; doi:10.1172/JCI32964DS1). Furthermore, resting membrane potential, basal firing rate, and whole-cell input resistance were not altered in POMC neurons of Pik3r1 POMCKO Pik3r2-/mice (Supplemental Table 1). The whole-cell capacitance of normal POMC and Pik3r1 POMCKO Pik3r2-/- POMC neurons were also statistically similar. These data suggest that POMC neuronal development is not altered in Pik3r1 POMCKO Pik3r2-/- neurons.

Normal corticotroph function in Pik3r1 POMCKO Pik3r2 ${ }^{-/-}$mice. Because hypercortisolism increases food intake, decreases energy expenditure, and can lead to obesity (38-40), we considered the possibility that Pik3r1 gene deletion in POMC-expressing corticotrophs might alter corticosterone release. We therefore examined the corticosterone levels in males seen under basal conditions and psychosocial-induced stress (41) in these mice. Basal levels of corticosterone did not differ between experimental mice and littermate controls (Supplemental Figure 2). We found that $30 \mathrm{~min}$ of social confrontation resulted in a similar increase in plasma corticosterone in Pik3r1 POMCKO Pik3r2 $2^{-/-}$mice and littermate controls, suggesting normal corticotroph function in the experimental mice.

Targeted POMC PI3K deletion disrupts insulin and leptin effects on neuronal activity. Insulin activates PI3K in the hypothalamus, and insulininduced modulation of cellular activity requires PI3K in POMC cells of the arcuate (42). Therefore, we used insulin to further test whether PI3K signaling was disrupted in our mouse model. We used wholecell patch-clamp recordings in WT mice that express GFP under the control of the POMC promoter. Similar to previous reports $(43,44)$,
$50 \mathrm{nM}$ insulin caused hyperpolarization from rest in 7 of 11 POMC neurons $(-7.7 \pm 1.2 \mathrm{mV} ; n=7$; Figure 5$)$. The hyperpolarization was accompanied by a $28 \%$ decrease in whole-cell input resistance, from $1,163.7 \pm 77.7 \mathrm{M}$ in control ACSF to $842.0 \pm 45.7 \mathrm{M}$ with insulin treatment ( $n=7$ from unidentified neurons; $P=0.004$, paired $t$ test). Extrapolation of the slope conductance revealed an estimated reversal potential of $-95 \pm 5 \mathrm{mV}(n=7)$ for the hyperpolarization, which is near the calculated $\mathrm{K}^{+}$equilibrium. Similar to previous reports, application of $200 \mu \mathrm{M}$ tolbutamide reversed the insulin-induced hyperpolarization ( $n=3$; Figure 5 ), suggesting that the insulin-induced hyperpolarization of hypothalamic neurons depends on activation of ATP-dependent $\mathrm{K}^{+}$channel conductance (11).

PI3K signaling was then assessed in POMC neurons from Pik3r1 POMCKO Pik3r2 $2^{-/}$mice by examining the insulin-induced suppression of cellular activity. Insulin $(50 \mathrm{nM})$ failed to influence the membrane potential in 10 of 12 POMC neurons from Pik3r1 POMCKO Pik $3 r 2^{-1-}$ mice $(0.3 \pm 0.4 \mathrm{mV} ; n=10$; Figure 5$)$. Of the 2 remaining cells, insulin application resulted in a small depolarization $(2 \mathrm{mV})$ in one cell and a small hyperpolarization $(-2 \mathrm{mV})$ in the other. These data suggest that PI3K signaling, as measured by acute insulin-induced inhibition of cellular activity, is severely disrupted in ARC POMC neurons from Pik3r1 POMCKO Pik3r2-/- mice.

Finally, we tested whether the absence of PI3K signaling in POMC neurons could prevent the observed leptin-induced excitation of cellular activity. In loose-patch recordings, leptin failed to increase unit activity in 4 of 5 POMC neurons from Pik3r1 POMCKO Pik3r2-mice (control, $1.3 \pm 0.1 \mathrm{~Hz}$; leptin, $1.6 \pm 0.2 \mathrm{~Hz} ; n=5, P=0.39$; Figure 2). Leptin application also failed to influence the membrane potential in 10 of 11 POMC neurons from these mice $(0.3 \pm 0.2 \mathrm{mV} ; n=11$; Figure 3). Leptin application in the remaining cell resulted in a small depolarization from rest $(3 \mathrm{mV})$. Moreover, whole-cell input resistance in all POMC cells examined from Pik3r1 POMCKO Pik3r2-/mice was also unaffected by leptin (control, 1,148.1 $\pm 111.1 \mathrm{M} \Omega$; 
A

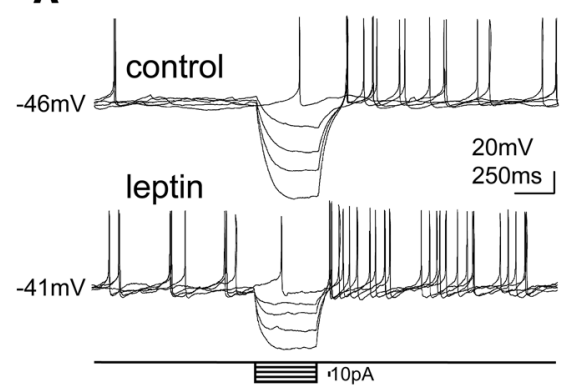

C

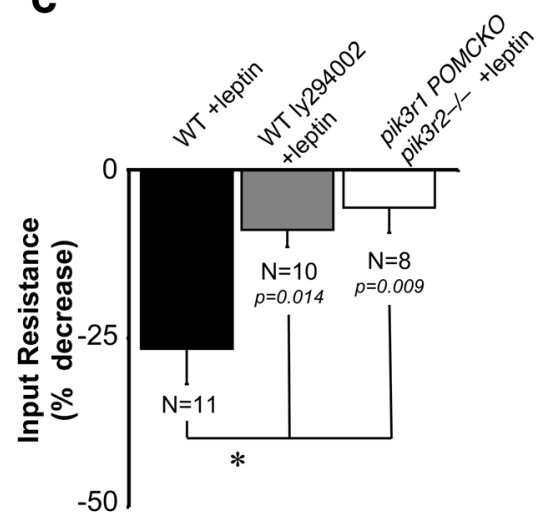

B

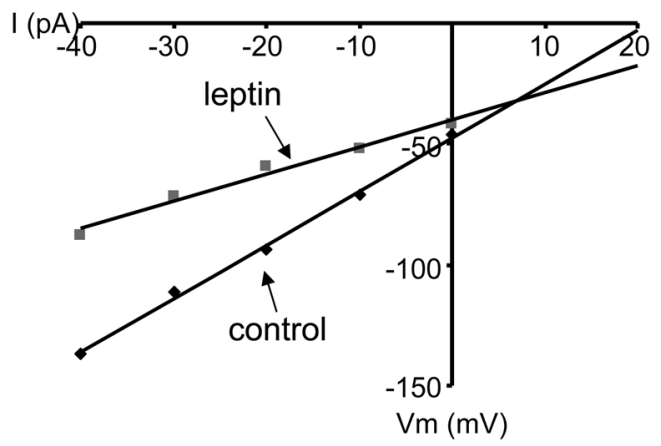

Figure 3

Leptin induces a decrease in whole-cell input resistance in POMC neurons. (A) Current-clamp recording from a WT neuron showing decreased voltage deflection and increased action potential frequency after leptin application (100 nM). (B) Current versus voltage (I-V) plot from same WT neuron illustrating a characteristic decrease in input resistance subsequent to leptin application. Shown are responses before (control) and during leptin application. (C) Decreased whole-cell input resistance from the neuron groups examined. $P$ values compared with WT treated with leptin alone are shown. leptin, $1,077.6 \pm 98.4 \mathrm{M} \Omega ; n=9, P=0.18$; Figure 3). Similarly, the leptin-induced inward current was not observed in POMC neurons from Pik3r1 POMCKO Pik $3 r 2^{-/-}$mice $(-3.0 \pm 1.0 \mathrm{pA} ; n=6)$. These data suggest that PI3K signaling is required for the leptin-induced excitation of ARC POMC neurons.

As previously described, in other cell types, deletion of a single PI3K regulatory isoform fails to suppress PI3K signaling $(17,18)$. Therefore, we also examined the effect of deleting p $85 \alpha$ alone from POMC neurons (Pik3r1 POMCKO mice). The basal activity before adding leptin was similar to that seen in p $85 \alpha$-intact POMC neurons (Supplemental Table 1). Importantly, $100 \mathrm{nM}$ leptin acutely activated POMC neurons from both WT and Pik3r1 POMCKO mice (Figure 2). There was also no significant difference between the leptin-induced depolarization and increase in firing rate of neurons from WT and Pik3r1 POMCKO mice. The contrast between the leptin responsiveness of Pik3r1 POMCKO POMC neurons and Pik3r1 POMCKO Pik3r2-/POMC neurons suggests that deletion of both p $85 \beta$ and $p 85 \alpha$ is required to disrupt PI3K activity in POMC neurons.

Targeted POMC PI3K disruption blunts responses to acute leptin administration. To directly assess leptin sensitivity in vivo, we compared the response of littermate controls and Pik3r1 POMCKO Pik3r2-/mice to exogenous leptin administration. Because body fat levels influence leptin sensitivity (45), mice were matched for body weight. Following surgical implantation of guide cannulae aimed the lateral ventricle, male mice ( $n=6-7$ per group) from each genotype were fasted overnight and injected i.c.v. with PBS vehicle or $6 \mu \mathrm{g}$ leptin. As shown in Figure 6, in control mice i.c.v. injection of leptin caused a significant reduction in food intake at $3 \mathrm{~h}$ after injection $(P=0.04)$ and body weight at $24 \mathrm{~h}$ after injection $(P=0.002)$ compared with saline-treated controls. However, in Pik3r1 POMCKO Pik $3 r 2^{-/-}$mice, i.c.v. leptin did not significantly affect food intake or body weight compared with vehicle. These results demonstrate that leptin-mediated inhibition of feeding is blunted in the absence of $\mathrm{p} 85 \alpha$ and $\mathrm{p} 85 \beta$ in POMC.

Energy homeostasis, fertility, and linear growth. Because leptin levels are generally increased in models of impaired leptin signaling, we measured leptin levels in Pik3r1 POMCKO Pik3r2-/- mice and littermate controls. Impairment of PI3K signaling in POMC cells did not affect circulating leptin levels. To further examine the effect of the targeted p85 deletion on long-term energy homeostasis, we examined body weight and food intake in Pik3r1 POMCKO Pik $3 r 2^{-1-}$ mice. Deletion of both $\alpha$ and $\beta$ subunits in POMC cells failed to influence long-term body weight regulation in males or females fed high-fat chow (Figure 7A). Food intake also did not differ between the groups (Figure 7B). To rule out the possibility that an increased adiposity phenotype was masked by a decline in lean mass, body composition was assessed in diet-induced obese mice using dual-energy X-ray absorptiometry. As shown in Figure 7C, fat percentage and lean mass were unaffected. Metabolic rate and respiratory quotient were similar between control and Pik3r1 POMCKO Pik3r2 $2^{-/-}$mice (Figure 8, A and C). Finally, hypothalamic POMC, NPY, and agouti-related protein (AgRP) mRNA levels were measured in these animals; no significant difference in expression levels was seen compared with controls (Figure 8B). Comparable expression levels were seen in mice 6-8 weeks of age (Supplemental Figure 3). These data demonstrate that PI3K signaling in POMC neurons is not required for long-term energy homeostasis.

In addition to regulating energy balance, leptin is also known to affect hypothalamic control of ovulation and body length (46-49). However, Pik3r1 POMCKO Pik3r2 $2^{-/-}$mice were similar to littermate controls in terms of pups per litter (Pik3r1 POMCKO Pik3r2-/, $6.1 \pm 0.8, n=13$; control, $6.7 \pm 0.5, n=14$ ), average time to conception (Pik3r1 POMCKO Pik3r2 ${ }^{-/-}, 5.6 \pm 2.6 \mathrm{~d}, n=14$; control, $7.2 \pm 2.4 \mathrm{~d}$, $n=15)$, and body length (Pik3r1 POMCKOPik $3 r 2^{-1-}$ males, $9.5 \pm 0.1 \mathrm{~cm}$, 
A

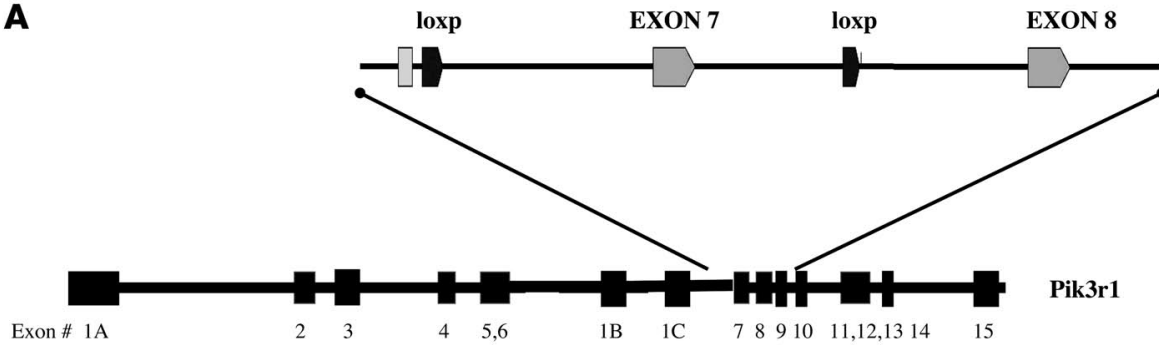

B

(+) Olf HYP Olf HYP Con Con KO KO

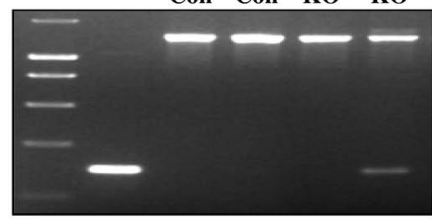

Figure 4

Deletion of exon 7 of Pik3r1 in genomic DNA from hypothalamic nuclei of Pik3r1 POMCKO Pik3r2-/- mice. (A) The 1,275-bp region between primer binding sites becomes $298 \mathrm{bp}$ in length when exon 7 is excised by cre recombinase. (B) Amplified genomic DNA from a Pik3r1 POMCKO Pik3r2-l- and littermate control (Con) mice. Tail DNA from a Pik3r1-- mouse is shown as a positive control (+). Olf, olfactory bulb DNA; HYP, DNA from whole hypothalamus; $\mathrm{DMH}$, dorsomedial hypothalamic nucleus; PVN, paraventricular nucleus. $n=6$; control males, $9.7 \pm 0.2 \mathrm{~cm}, n=8$ ). These data suggest that, at least in POMC neurons, the PI3K pathway is not required for fertility or linear growth.

\section{Discussion}

Selective deletion of leptin receptors in POMC neurons results in hyperleptinemia and causes moderate long-term weight gain (6). Whether this obese phenotype is dependent upon altered neuronal excitability or altered gene transcription was not clearly established previously. Moreover, while leptin directly depolarizes POMC neurons in the ARC (5), the cellular mechanism responsible has been a subject of debate. Previous studies showed that leptin activation of protein kinases (e.g., PI3K and MAPK) and subsequent phos-

A WT

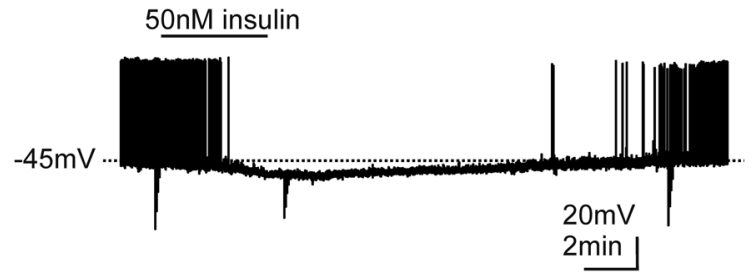

B

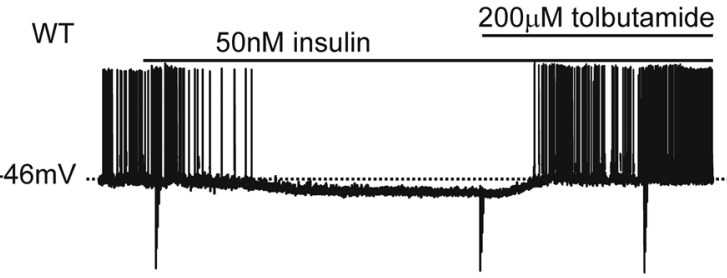

phorylation of target proteins occur rapidly and therefore might regulate membrane potential $(14,50)$. Our present results demonstrated that leptin acutely activates POMC neurons via a PI3K mechanism. In addition, we demonstrated that the POMC PI3K pathway contributes to the acute effects of exogenous leptin on feeding. These results are in accord with previous studies that have demonstrated abolition of leptin's suppression of feeding following PI3K inhibitor administration $(25,27)$.

While PI3K impairment in POMC neurons had striking, shortterm physiological consequences, the absence of POMC PI3K signaling had no detectable impact on long-term body weight homeostasis. These results are consistent with evidence that other intracellular signaling pathways, such as those targeting the transcription factor

C pik3r1 POMCKO pik3r2-/$50 \mathrm{nM}$ insulin
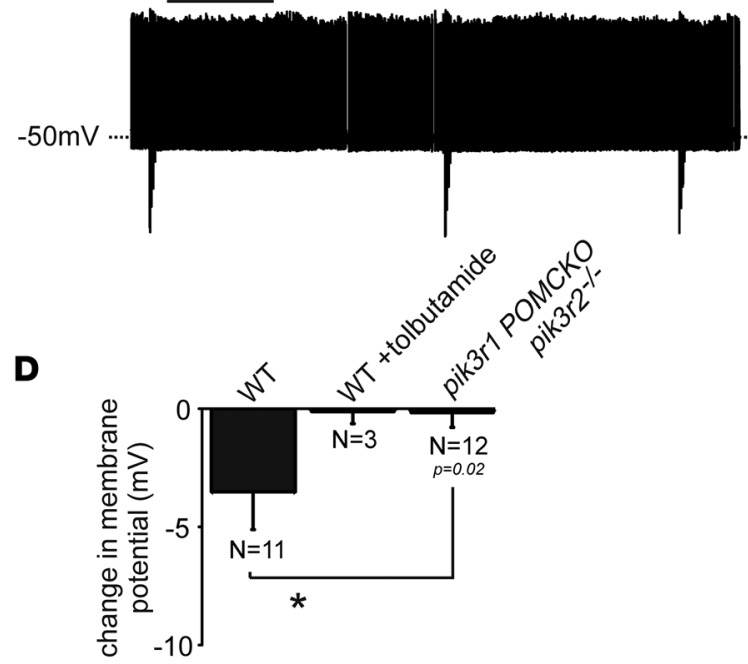

Figure 5

Insulin hyperpolarizes POMC neurons via a PI3K-dependent mechanism. (A) Current-clamp record depicting the hyperpolarization of a POMC neuron from rest by $50 \mathrm{nM}$ insulin. The hyperpolarization was reversible within $15 \mathrm{~min}$ of wash to control ACSF. Downward deflections are responses to rectangular current steps. (B) Current-clamp recording at resting membrane potential showing insulin-induced hyperpolarization $(50 \mathrm{nM})$ followed by tolbutamide $(200 \mu \mathrm{M})$ blockade of the insulin effect. (C) Sample trace illustrating the absence of insulin-induced hyperpolarization in POMC neurons from Pik3r1 POMCKO Pik3r2-/- mice. (D) Insulin-induced responses of identified POMC neurons from WT and Pik3r1 POMCKO Pik3r2--- mice. $P=0.02$, Pik3r1 POMCKO Pik3r2 ${ }^{-/-}$versus WT. 
A

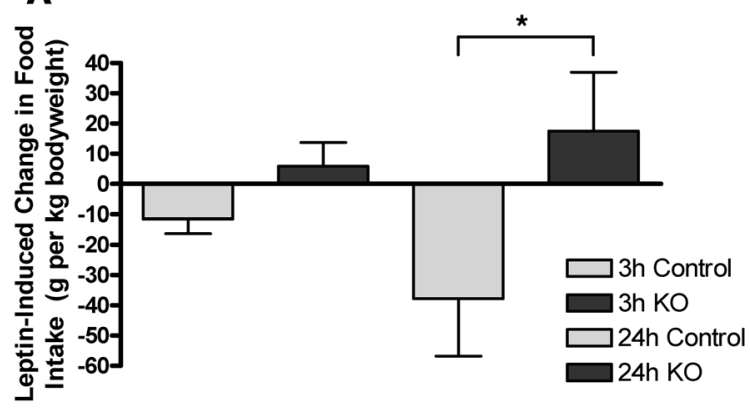

Figure 6

Leptin fails to suppress feeding in Pik3r1 POMCKO Pik3r2-l- mice. (A) Food consumption was measured 3 and 24 hours after leptin administration and compared with food consumption in each animal following saline administration. Values were normalized to kg body weight $(n=11-15)$. (B) Body weight 24 hours after injection in Pik3r1 POMCKO Pik3r2-/- mice and littermate controls lacking POMC-cre expression. Data are mean \pm SEM. ${ }^{*} P=0.0487,{ }^{* \star} P=0.0022$ versus saline-injected controls; Student's $t$ test.

STAT3, mediate many of leptin's actions on energy homeostasis. For example, Bates and colleagues demonstrated that disruption of leptin activation of STAT3 by a targeted mutation of the leptin receptor causes dramatic hyperphagia and decreased energy expenditure, resulting in profound obesity similar to $d b / d b$ mice (9). In addition, $\mathrm{Xu}$ et al. recently demonstrated that inactivating STAT3 in POMC neurons of female mice causes increased body weight and fat mass and reduces hypothalamic POMC expression (51). Interestingly, the authors also found that the responsiveness of these mice to acute leptin administration remained intact. While the precise role of IRS isoforms in leptin signaling via PI3K in POMC neurons has not been established, mice lacking Irs2 in POMC cells do not display increased
B

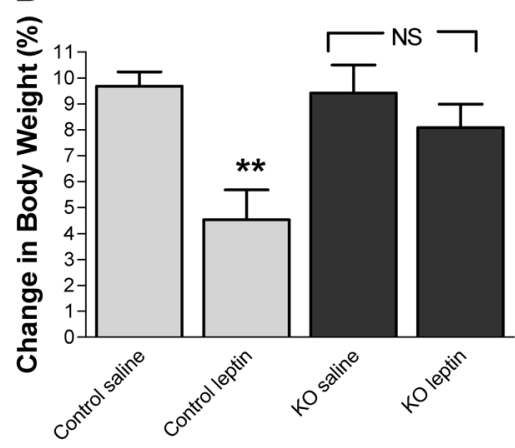

body weight, hyperleptinemia, or hyperphagia (43). Thus, our data are consistent with several findings demonstrating a role for both PI3Kdependent and -independent pathways in the actions of leptin in POMC neurons.

Several recent papers have demonstrated that proximity of the FoxO1 and STAT3 binding sites on the POMC promoter permits competition between the 2 factors, with FoxO1 inhibiting STAT3 stimulation of POMC gene transcription $(42,52)$. In addition, PI3K signaling would be expected to decrease nuclear localization of FoxO1 (52). Because our mice showed no increase in Pomc gene expression, our results suggest that alternate mechanisms maintain normal STAT3 transcriptional activity in mice with disrupted PI3K signaling.

When exposed to chronic hyperleptinemia via chronic central infusion (53), recombinant adeno-associated virus-mediated gene delivery (54), or as a result of diet-induced obesity (55), rodents gradually become unresponsive to the anorexic effects of leptin. A number of causes of this leptin resistance have been proposed, including impaired leptin-induced PI3K signaling $(56,57)$. However, Pik3r1 POMCKO Pik3r2 $2^{-/-}$mice, like WT mice, had both normal body weights and normal leptin levels, which suggests that Pik $3 r 1$ POMCKO Pik3r2 $2^{-/-}$mice remain leptin sensitive. These findings
Figure 7

Energy homeostasis, fertility, and linear growth. (A) Body weight curves and (B) cumulative food intake of Pik3r1 POMCKO Pik3r2--- mice and littermate controls lacking POMC-cre expression on high-fat chow. (C) Body fat percentage and lean mass in 8-month-old male and female diet-induced obese mice. (D) Serum leptin levels in 12-week-old male mice fed normal chow.
A

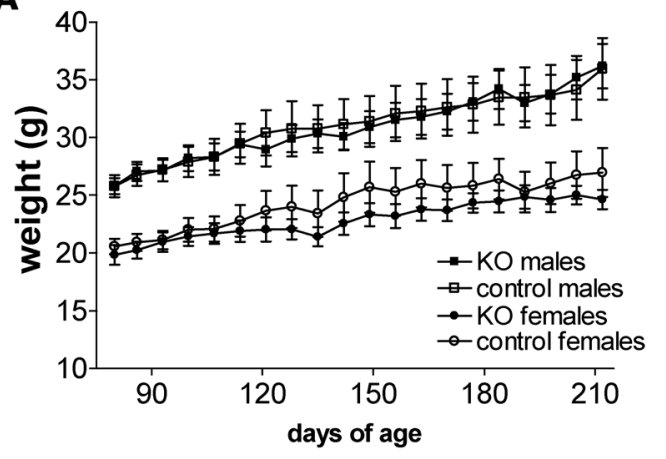

C

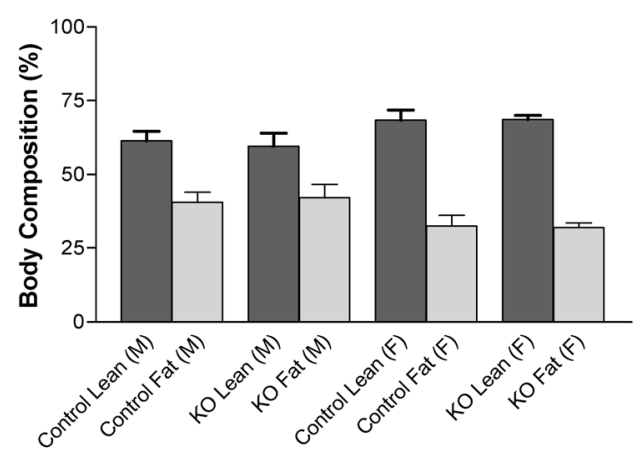

B

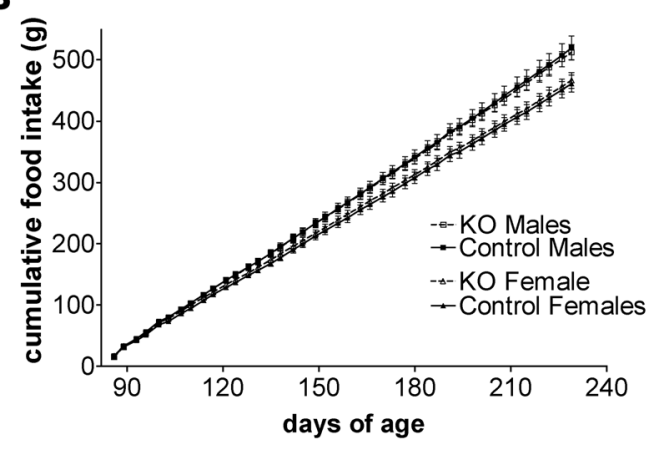

D

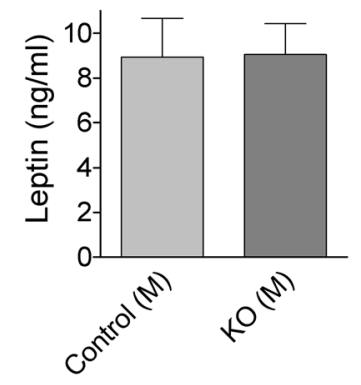


A
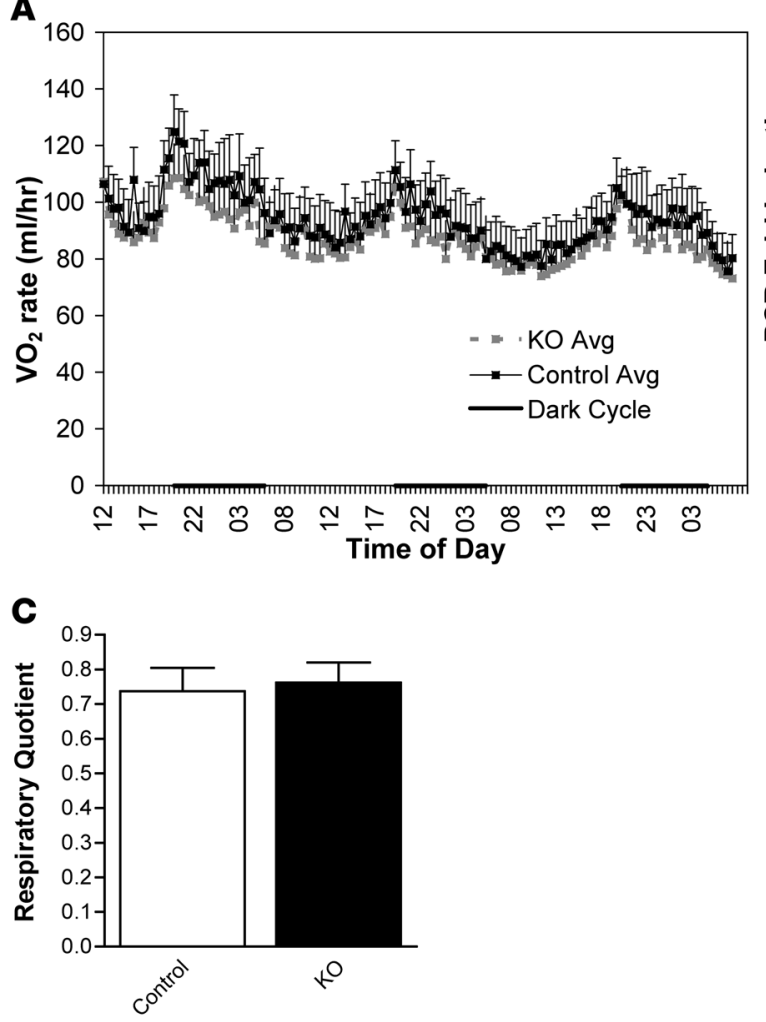

B

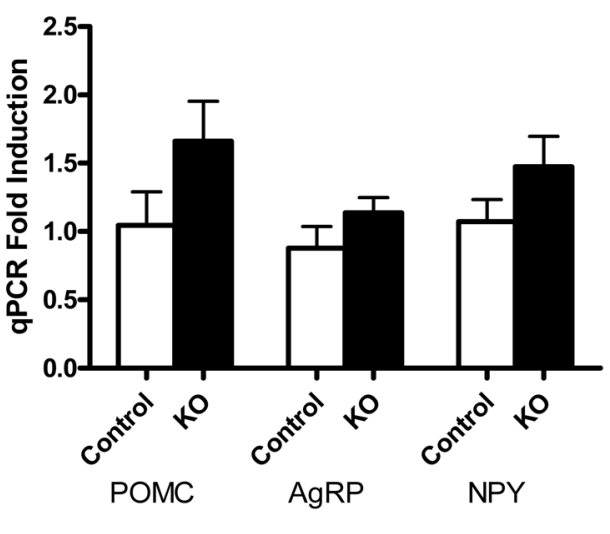

\section{Figure 8}

Metabolic rate and hypothalamic gene expression in mice lacking p85 in POMC neurons. (A) Oxygen consumption and (C) respiratory quotient was measured by indirect calorimetry and averaged over a 48-hour time period in male 8-week-old Pik3r1 POMCKO Pik3r2-/- mice and littermate controls lacking POMC-cre expression $(n=8)$. No significant difference was observed between groups. (B) NPY, AgRP, and POMC expression in hypothalami from 10-month-old male control $(n=7)$ or Pik3r1 POMCKO Pik3r2-l- mice $(n=5)$ as measured by quantitative PCR. argue against degradation of PI3K signaling in POMC neurons being solely responsible for obesity-related leptin resistance.

A model of intracellular PI3K function in POMC neurons. Previous studies have shown that deletion of $\mathrm{p} 85 \alpha$, its splice variants, and p $85 \beta$ results in severe disruption of PI3K signaling, while maintenance of one of these functional regulatory subunits of PI3K permits survival (58). For instance, mice with a liver-specific deletion of the p $85 \alpha$ regulatory subunit of PI3K exhibit an improvement of hepatic and peripheral insulin sensitivity (59). These findings are explained by the fact that in many cell types, $\mathrm{p} 85$ is stoichiometrically in excess of p110, and free p 85 can act as a dominant negative to inhibit PI3K signaling (16). In addition, free $\mathrm{p} 85$ can form a cytoplasmic sequestration complex with phosphorylated IRS-1, therefore limiting the ability of IRS-1 to activate PI3K at the membrane (60). It is therefore not surprising that our electrophysiological findings demonstrated that POMC neurons continued to respond to leptin when the $\mathrm{p} 85 \beta$ regulatory isoform was present. For similar reasons, p85 $\beta \mathrm{KO}$ mice have previously been shown to have a paradoxical increase in insulin sensitivity (35). This underlying phenotype may contribute to the lack of an observable increase in long-term body weight in our Pik3r1 POMCKO Pik3r2-/mice. Finally, it should be noted that the gene encoding the $\mathrm{p} 55 \gamma$ $\left(\mathrm{p} 55^{\mathrm{PIK}}\right)$ isoform of $\mathrm{p} 85$ was unaltered in this study. In contrast to the isoforms discussed above, p55 $\gamma$ expression barely exceeds background in the murine hypothalamus (28) and was considered unlikely to be involved in POMC PI3K signaling. In addition, the pharmacological inhibitors of PI3K signaling used in our electrophysiology experiments inhibit all classes of PI3Ks and resulted in the same effect as deletion of p85 $\alpha$, its splice variants, and $\mathrm{p} 85 \beta$. However, we cannot exclude the possibility that the $555 \gamma$ isoform plays some role in the nonacute actions of leptin.
Plum and colleagues recently concluded from the use of Pomccre/Pten ${ }^{l o x} /$ lox mice that leptin depolarizes and increases the firing rate of POMC neurons largely independent of PI3K signaling (61). It should be noted, however, that their model represents a constitutive elevation of PIP3, while Pik3r1 POMCKO Pik3r2 $2^{-/-}$mice presumably have very low PIP3 concentrations in POMC neurons. In addition, a direct evaluation of leptin's effects on PI3K signaling was not performed in the former study. We have directly assessed the effect of suppressing PI3K in POMC neurons in the context of direct leptin action and found that PI3K signaling was required for POMC neuronal excitation in response to leptin.

The question as to how leptin and insulin can excite and inhibit POMC cells, respectively, via an identical intracellular signaling cascade is an intriguing one. One possible explanation arises from the fact that leptin and insulin have each been shown to alter neuronal activity in only a percentage of POMC cells. Previous reports suggest that leptin activates $30 \%-90 \%$ of POMC cells (5, 43,62 ), while insulin inhibits $50 \%-70 \%$ of the POMC cell population $(43,62)$. It has not been resolved whether these subpopulations correspond to identical or disparate groups of neurons. It is possible that leptin-responsive POMC neurons may not be insulin sensitive, and vice versa. Additional studies are needed to understand the heterogeneity of POMC neuronal populations.

The data presented here supports a model in which leptin acutely activates ARC POMC neurons via a PI3K-dependent mechanism (Figure 9). Furthermore, PI3K appears necessary for the acute reduction in food intake and body weight by leptin, but not sufficient to alter long-term food intake or energy balance. These data suggest that although PI3K is a required downstream target for acute leptin regulation, other signaling cascades may be essential for leptin regulation of long-term energy balance. 


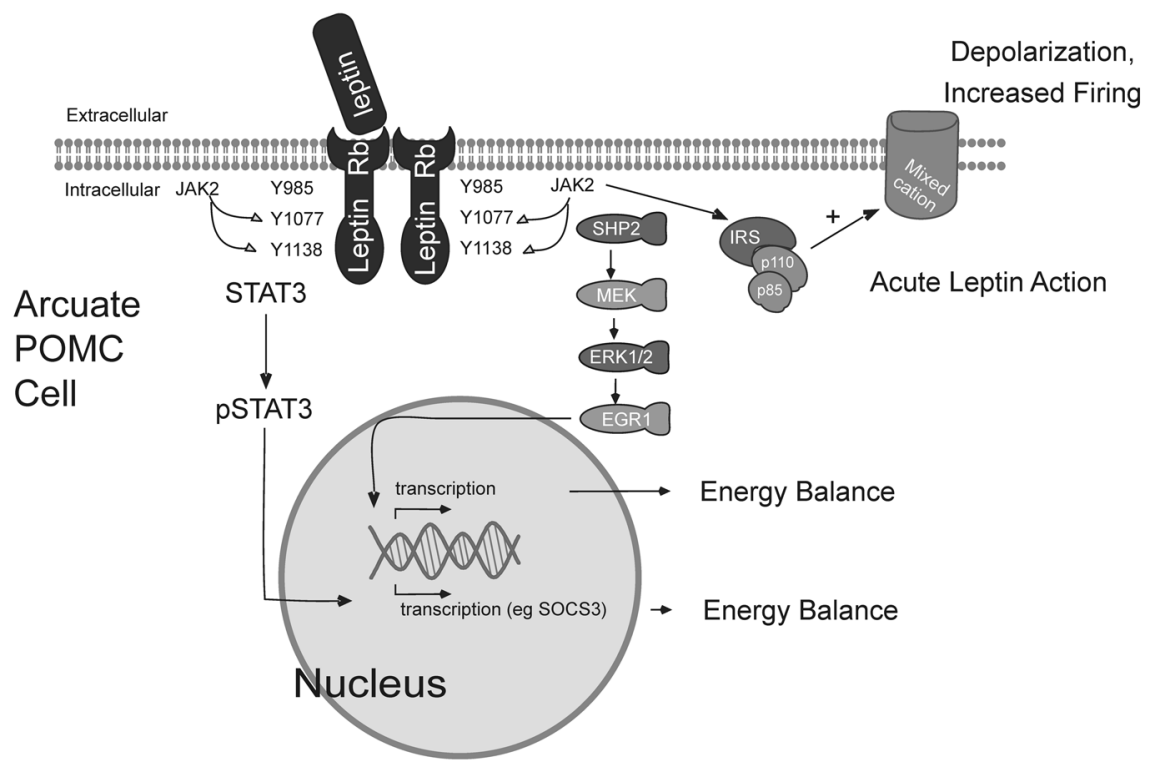

Figure 9

Model of leptin action in the arcuate POMC neuron. Acute stimulation of the long-form leptin receptor results in activation of the receptor-associated tyrosine kinase JAK2, which phosphorylates IRS proteins and in turn activates PI3K. PI3K subsequently activates a putative mixed-cation channel, which leads to depolarization and increased firing frequency responsible for POMC-mediated acute leptin actions. Sustained stimulation of the leptin receptor recruits $\mathrm{SH} 2$-containing tyrosine phosphatase (SHP2) to the leptin receptor tyrosine 985, which in turn regulates ERK activation. In addition, tyrosine 1138 of the leptin receptor recruits STAT3 and regulates transcriptional events such as the induction of SOCS3 required for long-term regulation of appetite and energy expenditure by leptin. The model predicts that PI3K is necessary for the acute actions of leptin in arcuate POMC neurons. However, other signaling cascades such as MAPK,SHP2, and STAT are likely candidates for the leptin-induced changes in long-term energy balance $(9,51,63)$.

In conclusion, our results suggest that the PI3K pathway, through its control of POMC neuronal excitation, plays a role in the detection of short-term alterations in leptin levels such as those caused by food deprivation (46). Moreover, PI3K plays a relatively minor role in the overall stability of the energy homeostatic system, indicating that during central adaptation to long-term excess energy availability, leptin signaling through alternative pathways such as STAT3 (9) or SH2-containing tyrosine phosphatase (44) predominate in POMC neurons. It remains to be determined whether the PI3K pathway plays an important role in energy homeostasis in other neurons such as NPY and/or AgRP cells and in other leptinmediated actions. Undoubtedly, cre-mediated deletion of PI3K subunits in targeted neuronal subtypes will be a powerful tool for formally examining these possibilities.

\section{Methods}

Animal care. Care of all animals and procedures was approved by the Beth Israel Deaconess Medical Center and the University of Texas Southwestern Medical Center Institutional Animal Care and Use Committees. Mice were housed in groups of $2-4$ at $22^{\circ} \mathrm{C}-24^{\circ} \mathrm{C}$ using a 14-h light/10-h dark cycle, with chow food (Teklad F6 Rodent Diet 8664, $4.05 \mathrm{kcal} / \mathrm{g}, 3.3 \mathrm{kcal} / \mathrm{g}$ metabolizable energy, $12.5 \%$ kcal from fat; Harlan Teklad) and water provided ad libitum. Mice with implanted catheters were housed individually. Mice were killed by $\mathrm{CO}^{2}$ narcosis.

Generation of Pik3r1 POMCKO Pik3r2-/- mice. Pomc-Cre mice (6) were mated with Pik3r1 ${ }^{\text {loxP } / l o x P}$ mice (63), Pik3r2 $2^{-/-}$mice (35), and B6;129Gt(ROSA)26Sor ${ }^{\text {tm2Sho }} / \mathrm{J}$ mice (The Jackson Laboratory). A breeding colony was

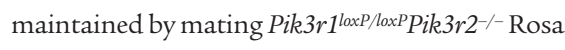
mice with Pik3r1 POMCKO Pik3r2-/- Rosa mice. Because Pik3r2-/- mice ubiquitously lacking p $85 \beta$ have a mild increase in insulin sensitivity (35), wild-type mice would be an inappropriate control for physiological studies, which compare phenotypes involving more than single POMC neurons. Thus, littermate controls with the same genetic background as experimental animals except for

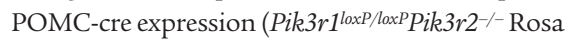
mice) were used for all experiments. Any mouse that tested positive for deletion of the Pik $3 r 1$ gene in tail tissue was excluded from all studies. Genotyping was performed according to protocols described previously $(6,17,34,35,64)$.

Characterization of Pik3r1 gene deletion in the bypothalamus. Adult mice were killed by carbon dioxide inhalation and immediately decapitated, and the brain was rapidly removed. The pituitary and olfactory bulbs were excised and snap frozen, and then sagittal brain sections of $1 \mathrm{~mm}$ thickness were cut via razor using a chilled Mouse Brain Matrice (Braintree Scientific Inc.). ARC, dorsomedial hypothalamic nucleus, paraventricular nucleus, and NTS were microdissected, snap frozen, and stored at $-80^{\circ} \mathrm{C}$. DNA was extracted using the Qiagen DNEasy kit using Polyf sodium salt (Roche) as a carrier. PCR was performed using Bio-Rad iTaq according to the manufacturer's instructions.

RNA isolation and cDNA preparation. RNA was extracted using an RNeasy kit (Qiagen) according to the manufacturer's directions. Genomic DNA contamination was eliminated by DNase treatment. Preparation of cDNA for quantitative PCR assays was performed according to published protocols (64) with the following changes: $2.4 \mu \mathrm{g}$ of RNA was first treated with $2 \mathrm{U}$ DNase I and $4.2 \mathrm{mM} \mathrm{MgCl}_{2}$ in a final volume of $40 \mu \mathrm{l}$. The reverse transcription reaction was carried out in $100 \mu \mathrm{l}$ final volume. Following cDNA synthesis, DEPC- $\mathrm{H}_{2} \mathrm{O}$ was added to increase the sample volume to $300 \mu \mathrm{l}$.

Quantitative PCR. Tissue mRNA levels were measured with an ABI 7900HT Sequence Detection System. Analysis of neuropeptide expression was performed using the TaqMan-based efficiency-corrected $\Delta \mathrm{Ct}$ assay with $10 \mathrm{ng}$ cDNA per reaction for 50 cycles (15). mRNAs with cycle times of 34 or greater were determined to be below detection. Primer concentrations were $75 \mathrm{nM}$ for cyclophilin. We used predeveloped assays purchased from Applied Biosystems for NPY, AgRP, and POMC. Quantitative PCR data were analyzed using ABI instrument software SDS2.1. Baseline values of amplification plots were set automatically, and threshold values were kept constant to obtain normalized cycle times and linear regression data. PCR efficiencies were calculated from the slope of the resulting standard curves. Normalized mRNA levels in arbitrary units were obtained by dividing the averaged, efficiency-corrected values for sample mRNA expression by that for cyclophilin RNA expression for each sample. The resulting values were expressed as fold change above control levels.

Hormone measurements. For leptin assays, tail vein blood was obtained from ad libitum chow-fed mice at 12 weeks of age. Serum was collected by centrifugation and assayed by ELISA (Crystal Chem Inc.) using a commercially available kit.

Resting plasma corticosterone levels were obtained between 2:00 p.m. and 4:00 p.m. from 8 mice of each group isolated for 3 days. The stress procedure 
was performed during the same time frame following the protocol described by Popova and colleagues (41). Briefly, psychosocial stress was induced in 8 mice of each strain by aggregation for $30 \mathrm{~min}$ in groups of 4 animals after 3 -day isolation in individual cages. Blood samples were taken after immediate decapitation of animals (within 30 seconds of handling). Blood was collected from the trunk in heparin-free tubes. The corticosterone concentration was measured from serum by ELISA (AssayDesigns Correlate-EIA Corticosterone kit) according to the manufacturer's instructions.

Electrophysiological studies. For these studies examining the behavior of single POMC neurons, 3 types of animals were used: POMC-GFP (5) mice expressing EGFP under the transcriptional control of the Pomc gene (referred to as WT), Pik3r1 POMCKO mice (lacking p $85 \alpha$ in POMC neurons) carrying a floxed Rosa-GFP allele, and Pik3r1 POMCKO Pik3r2- mice (also lacking p $85 \beta$ ) carrying a floxed Rosa-GFP allele. Three- to 8-week old mice were deeply anesthetized with isoflurane and transcardially perfused with a modified ice-cold ACSF (described below), in which an equiosmolar amount of sucrose was substituted for $\mathrm{NaCl}$. The mice were then decapitated, and the entire brain was removed as previously described $(5,12,31)$. After removal, brains were immediately submerged in ice-cold, carbogen-saturated $\left(95 \% \mathrm{O}_{2}\right.$ and $\left.5 \% \mathrm{CO}_{2}\right)$ ACSF $\left(126 \mathrm{mM} \mathrm{NaCl}, 2.5 \mathrm{mM} \mathrm{KCl}, 1.2 \mathrm{mM} \mathrm{MgCl}_{2}\right.$, $2.4 \mathrm{mM} \mathrm{CaCl}_{2}, 1.2 \mathrm{mM} \mathrm{NaH}_{2} \mathrm{PO}_{4}, 21.4 \mathrm{mM} \mathrm{NaHCO}_{3}$, and $11 \mathrm{mM}$ glucose). High $\mathrm{K}^{+}$buffer was made by replacing $56 \mathrm{mM} \mathrm{NaCl}$ by KCl. A brain block containing the hypothalamus was made. Coronal sections $(200-250 \mu \mathrm{M})$ were cut with a Leica VT1000S Vibratome and then incubated in oxygenated ACSF at room temperature for a least $1 \mathrm{~h}$ before recording.

Slices were transferred to the recording chamber and allowed to equilibrate for 10-20 min prior to recording. The slices were bathed in oxygenated $\operatorname{ACSF}\left(32^{\circ} \mathrm{C}-34^{\circ} \mathrm{C}\right)$ at a flow rate of approximately $2 \mathrm{ml} / \mathrm{min}$. Epifluorescence was briefly used to target fluorescent cells, at which time the light source was switched to infrared differential interference contrast imaging to obtain the whole-cell recording (Zeiss Axioskop FS2 Plus equipped with a fixed stage and a Hamamatsu C2741-60 charged-coupled device camera). Electrophysiological signals were recorded using an Axopatch 700B amplifier (Axon Instruments), low-pass filtered at $2-5 \mathrm{kHz}$, digitized at $88 \mathrm{kHz}$ (Neuro-corder; Cygnus Technology), stored on videotape, and analyzed offline on a PC with pCLAMP programs (Axon Instruments) or Mini-analysis (Synaptosoft). Recording electrodes had resistances of 2.5-5 M $\Omega$ when filled with the D-gluconate internal solution. Input resistance was assessed by measuring voltage deflection at the end of the response to a hyperpolarizing rectangular current pulse (400-500 ms of $-20 \mathrm{pA})$.

Pipette solution for whole-cell recording contained 110-128 mM K-gluconate, $10 \mathrm{mM} \mathrm{KCl}, 10 \mathrm{mM}$ HEPES, 1 mM EGTA, $0.3 \mathrm{mM} \mathrm{CaCl}_{2}, 1 \mathrm{mM}$ $\mathrm{MgCl}_{2}, 2-5 \mathrm{mM}(\mathrm{Mg})$-ATP, and $0.3 \mathrm{mM}(\mathrm{Na})-\mathrm{GTP}, \mathrm{pH}$ 7.3. For cellattached loose patch recordings, pipette solution contained $150 \mathrm{mM}$ $\mathrm{NaCl}, 3.5 \mathrm{mM} \mathrm{KCl}, 10 \mathrm{mM}$ HEPES, $10 \mathrm{mM}$ glucose, $2.5 \mathrm{mM} \mathrm{CaCl}_{2}$, and $1.3 \mathrm{mM} \mathrm{MgCl}$, $\mathrm{pH}$ 7.2-7.4. Wortmannin (10-100 nM; Alomone Laboratories), LY294002 (10 $\mu \mathrm{M}$; Calbiochem), PD98059 (25-50 $\mu \mathrm{M}$; Calbiochem), insulin (50 nM, Humulin-R $100 \mathrm{U} / \mathrm{ml}$; Lilly), and leptin (100 nM; provided by A.F. Parlow, Harbor-UCLA Medical Center, Torrance, California, USA; through the National Hormone and Peptide Program) were added to the ACSF for specific experiments. Wortmannin was dissolved in DMSO and added to ACSF to obtain a final DMSO concentration of less than $0.1 \%$. LY294002 was dissolved in 100\% ethanol, with the final ethanol concentration in ACSF less than $0.5 \%$. Solution containing leptin was typically perfused for 2-4 min. The leptin-induced effect was required to be associated temporally with leptin application, and the response had to be stable within a few minutes. For each recording, the averaged firing rate from every 20 -s epoch was taken as 1 data point. A total of $12-18$ data points that represent stable activity levels were taken to calculate mean and SD before and after application of leptin, respectively. A neuron was consid- ered activated or inhibited if the change in firing rate induced by leptin was greater than $\pm 3 \mathrm{SD}$ prior to leptin addition. A neuron was considered depolarized or hyperpolarized if a change in membrane potential was at least $2 \mathrm{mV}$ in amplitude.

ICV leptin administration. Stainless steel cannulae were inserted into the lateral ventricles $(0.5 \mathrm{~mm}$ caudal and $1 \mathrm{~mm}$ lateral from bregma; depth, $2.5 \mathrm{~mm}$ ) of anesthetized mice $(100 \mathrm{mg} / \mathrm{kg}$ ketamine hydrochloride and $6 \mathrm{mg} / \mathrm{kg}$ Xylazine i.p.). Mice were allowed to recover for at least 1 week before i.c.v. injection and were not used until they regained their presurgery weights. Cannulation placement was confirmed by demonstration of increased thirst after administration of angiotensin $(10 \mathrm{ng})$. A bolus injection of leptin $(6 \mu \mathrm{g} / \mathrm{mouse})$ or saline was administered i.c.v., and weight and food intake was measured at 0 and $45 \mathrm{~min}$ and 3 and $24 \mathrm{~h}$.

Feeding studies and body composition. High-fat diet-induced obese mice were housed individually for all food intake measurements. Body weight and chow consumption was measure once every 7 days. High-fat, high-sucrose diet (D-12331, 58\% kcal from fat, 26\% from sucrose, $5.557 \mathrm{kcal} / \mathrm{g}$; Research Diets) was replaced weekly in order to reduce spillage. At the conclusion of the diet-induced obesity study, mice were ketamine anesthetized and subjected to dual-energy X-ray absorptiometry (MEC Lunar Corp.) for analysis of fat and lean body composition.

Oxygen consumption. $\mathrm{O}_{2}$ consumption was measured for $48 \mathrm{~h}$ using an 8-chamber open-circuit Oxymax system that is a component of the Comprehensive Laboratory Animal Monitoring System (CLAMS; Columbus Instruments). Mice were housed individually in specially built Plexiglass cages ( $5 \mathrm{in}$. high, $4.5 \mathrm{in}$. wide, $8.5 \mathrm{in}$. deep) maintained at room temperature $\left(22^{\circ} \mathrm{C}\right)$ under an alternating 12 -h light/12-h dark cycle. Sample air was sequentially passed through $\mathrm{O}_{2}$ and $\mathrm{CO}_{2}$ sensors (Columbus Instruments) for determination of $\mathrm{O}_{2}$ and $\mathrm{CO}_{2}$ content. Food and water were provided ad libitum. Mice were acclimatized to monitoring cages for $48 \mathrm{~h}$ before data collection.

Statistics. Results are expressed as mean and SEM. Comparisons between 2 groups were made by unpaired 2-tailed Student's $t$ test or 1-way ANOVA with repeated measures, as appropriate. A $P$ value less than 0.05 was considered to be statistically significant.

\section{Acknowledgments}

The authors gratefully acknowledge Michael M. Scott, Jason Anderson, Michelle Choi, Frank Marino, Todd Williams, Brad Lampe, Sarah Greeley, and Charlotte Lee for their assistance in performing studies described in this paper. This work was supported by NIH grants 1F32DK066972 (to J.W. Hill), 1F32DK077487 (to K.W. Williams), PO1 DK56116 (to B.B. Lowell and J.K. Elmquist), DK53301 (to J.K. Elmquist), GM41890 (to L.C. Cantley), and R01 DK53301-07S2 (to B.B. Lowell, J.K. Elmquist, and M.A. Cowley); by an ADA Smith Family Foundation Pinnacle Program Award (to J.K. Elmquist); and by Takeda Pharmaceutical Company Ltd.

Received for publication June 11, 2007, and accepted in revised form February 13, 2008.

Address correspondence to: Joel K. Elmquist, University of Texas Southwestern Medical Center, 5323 Harry Hines Boulevard, Dallas, Texas 75390, USA. Phone: (214) 648-2911; Fax: (214) 648-5612; E-mail: joel.elmquist@utsouthwestern.edu.

Lewis C. Cantley, Bradford B. Lowell, and Joel K. Elmquist are co-senior authors.

Jennifer W. Hill and Kevin W. Williams are co-first authors. 
1. Zhang, Y., et al. 1994. Positional cloning of the mouse obese gene and its human homologue. Nature. 372:425-432.

2. Chen, H., et al. 1996. Evidence that the diabetes gene encodes the leptin receptor: identification of a mutation in the leptin receptor gene in $\mathrm{db} / \mathrm{db}$ mice. Cell. 84:491-495.

3. Lee, G.H., et al. 1996. Abnormal splicing of the leptin receptor in diabetic mice. Nature. 379:632-635.

4. Elias, C.F., et al. 2000. Chemical characterization of leptin-activated neurons in the rat brain. J. Comp. Neurol. 423:261-281.

5. Cowley, M.A., et al. 2001. Leptin activates anorexigenic POMC neurons through a neural network in the arcuate nucleus. Nature. 411:480-484.

6. Balthasar, N., et al. 2004. Leptin receptor signaling in POMC neurons is required for normal body weight homeostasis. Neuron. 42:983-991.

7. Banks, A.S., Davis, S.M., Bates, S.H., and Myers, M.G., Jr. 2000. Activation of downstream signals by the long form of the leptin receptor. J. Biol. Chem. 275:14563-14572.

8. Muraoka, O., et al. 2003. Leptin-induced transactivation of NPY gene promoter mediated by JAK1, JAK2 and STAT3 in the neural cell lines. Neurochem. Int. 42:591-601.

9. Bates, S.H., et al. 2003. STAT3 signalling is required for leptin regulation of energy balance but not reproduction. Nature. 421:856-859.

10. Bohannon, N.J., et al. 1986. Identification of binding sites for an insulin-like growth factor (IGF-I) in the median eminence of the rat brain by quantitative autoradiography. Endocrinology. 119:943-945.

11. Spanswick, D., Smith, M.A., Groppi, V.E., Logan, S.D., and Ashford, M.L. 1997. Leptin inhibits hypothalamic neurons by activation of ATP-sensitive potassium channels. Nature. 390:521-525.

12. Williams, K.W., and Smith, B.N. 2006. Rapid inhibition of neural excitability in the nucleus tractus solitarii by leptin: implications for ingestive behaviour. J. Physiol. 573:395-412.

13. Williams, K.W., Zsombok, A., and Smith, B.N. 2006. Rapid inhibition of neurons in the dorsal motor nucleus of the vagus by leptin. Endocrinology. 148:1868-1881.

14. Xu, A.W., et al. 2005. PI3K integrates the action of insulin and leptin on hypothalamic neurons. J. Clin. Invest. 115:951-958.

15. Bookout, A.F., and Mangelsdorf, D.J. 2003. Quantitative real-time PCR protocol for analysis of nuclear receptor signaling pathways. Nucl. Recept. Signal. 1:e012.

16. Luo, J., and Cantley, L.C. 2005. The negative regulation of phosphoinositide 3-kinase signaling by $\mathrm{p} 85$ and its implication in cancer. Cell Cycle. 4:1309-1312.

17. Luo, J., et al. 2005. Class IA phosphoinositide 3kinase regulates heart size and physiological cardiac hypertrophy. Mol. Cell. Biol. 25:9491-9502.

18. Ueki, K., et al. 2002. Molecular balance between the regulatory and catalytic subunits of phosphoinositide 3-kinase regulates cell signaling and survival. Mol. Cell. Biol. 22:965-977.

19. Shyng, S.L., and Nichols, C.G. 1998. Membrane phospholipid control of nucleotide sensitivity of KATP channels. Science. 282:1138-1141.

20. Baukrowitz, T., et al. 1998. PIP2 and PIP as determinants for ATP inhibition of KATP channels. Science. 282:1141-1144.

21. Morrison, C.D., Morton, G.J., Niswender, K.D., Gelling, R.W., and Schwartz, M.W. 2005. Leptin inhibits hypothalamic Npy and Agrp gene expression via a mechanism that requires phosphatidylinositol 3-OH-kinase signaling. Am. J. Physiol. Endocrinol. Metab. 289:E1051-E1057.

22. Morton, G.J., et al. 2005. Leptin regulates insulin sensitivity via phosphatidylinositol-3-OH kinase signaling in mediobasal hypothalamic neurons. Cell Metab. 2:411-420.

23. Carvalheira, J.B., et al. 2005. Cross-talk between the insulin and leptin signaling systems in rat hypothalamus. Obes. Res. 13:48-57.

24. Mirshamsi, S., et al. 2004. Leptin and insulin stimulation of signalling pathways in arcuate nucleus neurones: PI3K dependent actin reorganization and KATP channel activation. BMC Neurosci. 5:54.

25. Rahmouni, K., Haynes, W.G., Morgan, D.A., and Mark, A.L. 2003. Intracellular mechanisms involved in leptin regulation of sympathetic outflow. Hypertension. 41:763-767.

26. Zhao, A.Z., Huan, J.N., Gupta, S., Pal, R., and Sahu, A. 2002. A phosphatidylinositol 3-kinase phosphodiesterase 3B-cyclic AMP pathway in hypothalamic action of leptin on feeding. Nat. Neurosci. 5:727-728.

27. Niswender, K.D., et al. 2001. Intracellular signalling. Key enzyme in leptin-induced anorexia. Nature. 413:794-795.

28. Horsch, D., and Kahn, C.R. 1999. Region-specific mRNA expression of phosphatidylinositol 3-kinase regulatory isoforms in the central nervous system of C57BL/6J mice. J. Comp. Neurol. 415:105-120.

29. Dhillon, H.F., et al. 2006. Leptin directly activates SF1 neurons in the VMH, and this action by leptin is required for normal body-weight homeostasis. Neuron. 49:191-203.

30. Heisler, L., et al. 2006. Serotonin reciprocally regulates melanocortin neurons to modulate food intake. Neuron. 51:239-249.

31. van den Top, M., Lee, K., Whyment, A.D., Blanks, A.M., and Spanswick, D. 2004. Orexigen-sensitive NPY/AgRP pacemaker neurons in the hypothalamic arcuate nucleus. Nat. Neurosci. 7:493-494.

32. Munzberg, H., et al. 2007. Appropriate inhibition of orexigenic hypothalamic arcuate nucleus neurons independently of leptin receptor/STAT3 signaling. J. Neurosci. 27:69-74.

33. Powis, J.E., Bains, J.S., and Ferguson, A.V. 1998. Leptin depolarizes rat hypothalamic paraventricular nucleus neurons. Am. J. Physiol. 274:R1468-R1472.

34. Fruman, D.A., et al. 1999. Impaired B cell development and proliferation in absence of phosphoinositide 3-kinase p85alpha. Science. 283:393-397.

35. Ueki, K., et al. 2002. Increased insulin sensitivity in mice lacking p85beta subunit of phosphoinositide 3-kinase. Proc. Natl. Acad. Sci. U. S. A. 99:419-424.

36. Bronstein, D.M., Schafer, M.K., Watson, S.J., and Akil, H. 1992. Evidence that beta-endorphin is synthesized in cells in the nucleus tractus solitarius: detection of POMC mRNA. Brain Res. 587:269-275.

37. Elias, C.F., et al. 1999. Leptin differentially regulates NPY and POMC neurons projecting to the lateral hypothalamic area. Neuron. 23:775-786.

38. Tempel, D.L., and Leibowitz, S.F. 1994. Adrenal steroid receptors: interactions with brain neuropeptide systems in relation to nutrient intake and metabolism. J. Neuroendocrinol. 6:479-501.

39. Strack, A.M., Horsley, C.J., Sebastian, R.J., Akana, S.F., and Dallman, M.F. 1995. Glucocorticoids and insulin: complex interaction on brown adipose tissue. Am. J. Physiol. 268:R1209-R1216.

40. Solomon, J., and Mayer, J. 1973. The effect of adrenalectomy on the development of the obese-hyperglycemic syndrome in ob-ob mice. Endocrinology. 93:510-512.

41. Popova, N.K., Maslova, L.N., Morosova, E.A., Bulygina, V.V., and Seif, I. 2006. MAO A knockout attenuates adrenocortical response to various kinds of stress. Psychoneuroendocrinology. 31:179-186.

42. Kitamura, T., et al. 2006. Forkhead protein FoxO1 mediates Agrp-dependent effects of leptin on food intake. Nat. Med. 12:534-540.

43. Choudhury, A.I., et al. 2005. The role of insulin receptor substrate 2 in hypothalamic and beta cell function. J. Clin. Invest. 115:940-950.

44. Zhang, E.E., Chapeau, E., Hagihara, K., and Feng, G.S. 2004. Neuronal Shp2 tyrosine phosphatase controls energy balance and metabolism. Proc. Natl. Acad. Sci. U. S. A. 101:16064-16069.

45. Ahima, R.S., and Flier, J.S. 2000. Leptin. Annu. Rev. Physiol. 62:413-437.

46. Ahima, R.S., et al. 1996. Role of leptin in the neuroendocrine response to fasting. Nature. 382:250-252.

47. Coleman, D.L. 1978. Obese and diabetes: two mutant genes causing diabetes-obesity syndromes in mice. Diabetologia. 14:141-148.

48. Coleman, D.L. 1982. Diabetes-obesity syndromes in mice. Diabetes. 31:1-6.

49. Takeda, S., et al. 2002. Leptin regulates bone formation via the sympathetic nervous system. Cell. 111:305-317.

50. Myers, M.G., Jr. 2004. Leptin receptor signaling and the regulation of mammalian physiology. Recent. Prog. Horm. Res. 59:287-304.

51. Xu, A., Marie, L., Kaelin, C.B., and Barsh, G.S. 2007. Inactivation of signal transducer and activator of transcription 3 in proopiomelanocortin (Pomc) neurons causes decreased pomc expression, mild obesity, and defects in compensatory refeeding. Endocrinology. 148:72-80.

52. Kim, M., et al. 2006. Role of hypothalamic Foxo1 in the regulation of food intake and energy homeostasis. Nat. Neurosci. 9:901-906.

53. Pal, R., and Sahu, A. 2003. Leptin signaling in the hypothalamus during chronic central leptin infusion. Endocrinology. 144:3789-3798.

54. Scarpace, P.J., Matheny, M., Zolotukhin, S., Tumer, N., and Zhang, Y. 2003. Leptin-induced leptin resistant rats exhibit enhanced responses to the melanocortin agonist MT II. Neuropharmacology. 45:211-219.

55. Van Heek, M., et al. 1997. Diet-induced obese mice develop peripheral, but not central, resistance to leptin. J. Clin. Invest. 99:385-390.

56. Sahu, A. 2003. Leptin signaling in the hypothalamus: emphasis on energy homeostasis and leptin resistance. Front. Neuroendocrinol. 24:225-253.

57. Sahu, A., and Metlakunta, A.S. 2005. Hypothalamic phosphatidylinositol 3-kinase-phosphodiesterase 3B-cyclic AMP pathway of leptin signalling is impaired following chronic central leptin infusion. J. Neuroendocrinol. 17:720-726.

58. Brachmann, S.M., et al. 2005. Role of phosphoinositide 3 -kinase regulatory isoforms in development and actin rearrangement. Mol. Cell. Biol. 25:2593-2606.

59. Taniguchi, C., et al. 2006. Phosphoinositide 3kinase regulatory subunit p85alpha suppresses insulin action via positive regulation of PTEN. Proc. Natl. Acad. Sci. U. S. A. 103:12093-12097.

60. Luo, J., Field, S.J., Lee, J.Y., Engelman, J.A., and Cantley, L.C. 2005. The $\mathrm{p} 85$ regulatory subunit of phosphoinositide 3-kinase down-regulates IRS-1 signaling via the formation of a sequestration complex. J. Cell Biol. 170:455-464.

61. Plum, L., et al. 2006. Enhanced PIP3 signaling in POMC neurons causes KATP channel activation and leads to diet-sensitive obesity. J. Clin. Invest. 116:1886-1901.

62. Claret, M., et al. 2007. AMPK is essential for energy homeostasis regulation and glucose sensing by POMC and AgRP neurons. J. Clin. Invest. 117:2325-2336.

63. Luo, J., et al. 2006. Loss of class IA PI3K signaling in muscle leads to impaired muscle growth, insulin response, and hyperlipidemia. Cell Metab. 3:355-366.

64. Mao, X., Fujiwara, Y., Chapdelaine, A., Yang, H., and Orkin, S.H. 2001. Activation of EGFP expression by Cre-mediated excision in a new ROSA26 reporter mouse strain. Blood. 97:324-326. 